\title{
Clients' Perception of the Role of Transportation to the Hospital and Level of Hospital in Reducing Maternal Mortality in Calabar, Nigeria
}

\author{
Duke Emon Umoe ${ }^{1}$, Lukpata Felicia ${ }^{1}$, Agba Mathias ${ }^{1} \&$ Nwakwue C. Ndukaku ${ }^{1}$ \\ ${ }^{1}$ Department of Nursing Science, University of Calabar, Calabar, Nigeria \\ Correspondence: Duke Emon Umoe, Department of Nursing Science, University of Calabar, Calabar, Nigeria
}

Received: December 4, 2019 Accepted: July 4, 2020 Online Published: November 30, 2020

doi:10.5539/gjhs.v12n13p165 URL: https://doi.org/10.5539/gjhs.v12n13p165

\begin{abstract}
Transportation is vital in accessing healthcare services as well as reducing maternal mortality. This study examined clients' perception of the role of transportation to the hospital and level of hospital in reducing maternal mortality in Calabar. This study was a cross-section descriptive design. Four (4) research questions were developed for the study. A total of 220 participants were recruited by proportionate sampling technique. Respondents were selected from four clinic days Tuesdays, Wednesdays, Thursdays and Fridays in each visit for a period of two weeks were used for the study. A structured questionnaire was used to collect data. The data were analysed using frequencies and percentages. The finding of the study revealed that: $153(68 \%)$ agreed that good transportation increases the number of times participants go for an antenatal visit. $159(72 \%)$ of the respondents viewed that good roads and vehicles make a journey to the hospital quick and easy. 177 (62\%) opined that the best way to visit the hospital is by one's car or a taxi drop. 203 (93\%) agreed that hospital has skilled midwives and doctors; $153(70 \%)$ agreed that level of the hospital is reflective of low maternal and infant deaths; $159(72 \%)$ agreed that healthcare team are highly skilled in handling both complicated and uncomplicated deliveries. 181 (78\%) supports the notion that transportation plays a huge role in the reduction of maternal mortality in Calabar; $148(67 \%)$ agreed that good road network has an indirect role in reducing maternal mortality in Calabar; $146(67 \%)$ opined that controlled traffic helps reduced maternal mortality in Calabar, and $159(71 \%)$ agreed that lack of access to transport for women in labour can increase stillbirth and maternal death rates. The study concludes that a good road network should be provided to reduce maternal mortality in Calabar.
\end{abstract}

Keywords: client's perception, the role of transportation, delays in healthcare, hospital infrastructure, pregnant women, maternal health

\section{Introduction}

Globally, maternal mortality is unacceptably high. The 2017 statistics of death indicates that an estimated 810 women died daily with a total of 295, 000 deaths recorded in the period (World Health Organization, 2019). The majority of these deaths seems to be avoidable. Basic amenities such as transportation and infrastructures play a crucial role in reducing maternal mortalities. By so doing achieve meet the Sustainable Development Goal (SDG) 3: Promoting good health and wellbeing to all and all ages. As mortality declined, inequality has become more apparent as the risk of death is high among the most vulnerable women who cannot access care or lack resource to access maternal and newborn care in poorest nations like Nigeria (The United States Agency for International Development, 2014). Although most maternal deaths can be preventable, efforts are now channelled at pregnant women. This is because, among the 189 million women who are pregnant annually, 122 million have a live birth, about 3 million suffer stillbirth while $10 \%$ of mothers suffer from a maternal complication during pregnancy or delivery period, and up to $40 \%$ may have morbidities or disabilities post-birth that are attributable to the pregnancy or during delivery despite improvement in maternal and newborn care (Admasu, Haile-Mariam, \& Bailey, 2011; Kim et al., 2012; Abegunde et al., 2015; Umoe et al., 2020a)

On the one hand, good Transportation facilitates timely arrival to the hospital. On the other hand, the availability of basic infrastructures in the hospital ensures affordable delivery of basic health services. Both connect communities to health facilities and can empower vulnerable pregnant women (Kim et al., 2012; Shrestha et al., 2012; Kitui, Lewis, \& Davey, 2013; Umoe et al., 2020b). Despite the evidence supporting the role of transportation in the reduction of maternal mortality (Campbell, Graham, \& Lancet Maternal Survival Series steering group, 2006; Haines et al., 2009; Alkema et al., 2016), most developing countries like Nigeria are yet to 
fully acknowledge and understand the role of transport and infrastructure in improving the health of vulnerable pregnant women. Sadly, many remote areas still lack accessible roads and poor transportation services for pregnant women to access health services during pregnancy or while in labour. A cross-sectional study by Atuoye and colleagues (2015) which explored the transportation barriers to accessing maternal and child healthcare services in rural Ghana showed that lack of vehicle transportation was a major obstacle suppressing the potential positive impact of community-based health planning services on maternal and child health. Similarly, another study by Fiagbe, Asamoah and Oduro (2012) showed that majority of the respondents 55.8\% of pregnant women and $36.7 \%$ of health management respondents described the transportation services for maternal health services as being good. Therefore hospital infrastructures contribute positively to improved maternal and child health. To this end, the study was conducted to assess clients' perception of the role of transportation to the hospital and level of hospital in transportation in reducing maternal mortality in Calabar, Nigeria.

\subsection{Research Question}

The research questions are:

1). How do clients perceive the role of transportation to the hospital in Calabar?

2). What is the perception of clients on the level of hospital in the reduction of maternal mortality in Calabar?

3). What are the transport-related barriers that delay access to maternal health services in UCTH?

4). Are there hindrances to access to hospital infrastructure in the provision of maternal healthcare services in UCTH?

\section{Material and Methods}

The sites for this study was the University of Calabar Teaching Hospital. The hospital has two annexes (Antigua \& Egerton, n.d.). Both the hospital and the annexes provide antenatal services. While UCTH is located in the urban area of Calabar, the annexes are in the rural part of Calabar.

\subsection{Research Design}

The study adopted a cross-section descriptive design.

\subsection{Population}

The populations consisted of all pregnant women who registered/booked for antenatal and maternal-newborn services at UCTH and the annexes at Antigua and Egerton, Calabar. A total of four hundred and ninety (490) women attend the antenatal clinic monthly in the three settings. Sample size determination was by radius and interval of convergence of power series. A sample size of 220 pregnant women was recruited using a proportionate sampling technique. The researcher selected the participants through simple random techniques; this enabled the participant to have equal chances of being selected for the study. At each visit 30,25 and 20 participants were selected from four clinic days Tuesdays, Thursdays and Fridays for a period of two weeks to give a total of 220 participants.

\subsection{Ethical Considerations}

Ethical consideration was obtained from the ethics committee of UCTH. Verbal and written consent was obtained from the participants. Anonymity and confidentiality were maintained for all participants. Participation was voluntary.

\subsection{Data Collection Method}

A validated and structured questionnaire was used for data collection. The researchers used one trained research assistant qualification to assist in data collection in Egerton due to distance.

\subsection{Data Analysis}

The data collected from the respondents were coded and scrutinized. The data was analysed using descriptive statistics using frequencies and simple percentages. The major dependent variables are pregnant women, remote areas of Antigua and Egerton, access maternal health services, and provision of maternal health care services. A total of 220 questionnaires were administered. All questionnaires were returned complete. 
Table 1. Socio-demographic data of respondents $(n=220)$

\begin{tabular}{llcc}
\hline \multicolumn{1}{c}{ Variables } & Frequency & Percentage (\%) \\
\hline 1 & Age in years: & 60 & \\
& $15-24$ & 90 & $25 \%$ \\
& $25-34$ & 60 & $41.7 \%$ \\
$35-44$ & 10 & $25 \%$ \\
& 45 and above & & $8.3 \%$ \\
\hline 2 & Educational qualification: & 40 & \\
& Primary & 80 & $18.2 \%$ \\
& Secondary & 90 & $36.4 \%$ \\
& Tertiary & 10 & $40.9 \%$ \\
No formal education & & $4.5 \%$ \\
\hline 3 & Occupation & 37 & $16.8 \%$ \\
Housewife & 80 & $36.4 \%$ \\
Civil servant & 43 & $19.5 \%$ \\
Farmers & 60 & $27.3 \%$ \\
\hline
\end{tabular}

\section{Results}

\subsection{Research Question 1: How do Clients Perceive the Role of Transportation to the Hospital in Calabar?}

From Table 2 seven (7) questions were used to elicit the answer to research question 1. Question 4 was asked if good transportation increases the number of times pregnant women go for an antenatal visit, 105 (48\%) strongly agreed, $45(20 \%)$ agreed, $50(23 \%)$ strongly disagreed, $17(8 \%)$ disagreed while $3(1 \%)$ were undecided. Question 5 enquired if access to transport motivates the participants to go on an antenatal visit. The analysis shows that $93(42 \%), 52(24 \%), 47(21 \%)$, and $23(11 \%)$ strongly agreed, agreed, strongly disagreed and disagreed respectively. Question 6 was on if bad roads cause waist or body pains when they travel to and from the hospital. Responses show that 64 (29\%) strongly agreed, 53 (24\%) agreed, 69 (31\%) strongly agreed, 28 $(13 \%)$ agreed and $7(3 \%)$ were undecided. Question 7 was on traffic during rush hour is frustrating due to the quest to arrive early $56(25 \%)$ strongly agreed, 52 (24\%) agreed, $63(29 \%)$ strongly disagreed, $32(15 \%)$ agreed while $17(7 \%)$ were undecided. Question 8 was on if good roads and vehicles make a journey to the hospital is quick and with ease. $89(40 \%)$ strongly agreed, $70(32 \%)$ agreed, $32(15 \%)$ strongly disagreed, $24(11 \%)$, while 5 (2\%) were undecided. Question 9 viewed that commercial vehicles in Calabar are not conducive for pregnant women. 98 (44\%) strongly agreed, 57 (26\%) agreed, 53 (25\%) strongly disagreed, $12(5 \%)$ disagreed. Question 10 was on the best way to travel to the hospital is by private car or a taxi drop. 120 (56\%) strongly agreed, 57 (26\%), $21(9 \%)$ strongly disagreed and $22(9 \%)$ disagreed.

Table 2. The perception of clients on the role of transportation in Calabar $(\mathrm{n}=220)$

\begin{tabular}{|c|c|c|c|c|c|c|c|c|c|c|c|}
\hline & Items & $\mathbf{S A}$ & $\%$ & $\mathbf{A}$ & $\%$ & SD & $\%$ & $\mathbf{D}$ & $\%$ & $\mathbf{U}$ & $\%$ \\
\hline 4 & $\begin{array}{l}\text { Good transportation increase the number of times I go for an } \\
\text { antenatal visit }\end{array}$ & 105 & 48 & 45 & 20 & 50 & 23 & 17 & 8 & 3 & 1 \\
\hline 5 & I go on antenatal visits when I can access transport to the clinic & 93 & 42 & 57 & 26 & 47 & 21 & 23 & 11 & 0 & 0 \\
\hline 6 & Bad roads cause waist pain when I travel for long to the hospital & 64 & 29 & 52 & 24 & 69 & 31 & 28 & 13 & 7 & 3 \\
\hline 7 & $\begin{array}{l}\text { Traffic during rush hour is frustrating as I have to get to the } \\
\text { clinic early. }\end{array}$ & 56 & 25 & 52 & 24 & 63 & 29 & 32 & 15 & 17 & 7 \\
\hline 8 & $\begin{array}{l}\text { Good road and vehicles make a journey to the hospital quick } \\
\text { and with ease }\end{array}$ & 89 & 40 & 70 & 32 & 32 & 15 & 24 & 11 & 5 & 2 \\
\hline
\end{tabular}


9 The commercial vehicles in Calabar are not conducive for $\begin{array}{lllllllllll}98 & 44 & 57 & 26 & 53 & 25 & 12 & 5 & 0 & 0\end{array}$ pregnant women

10 The best way to visit the hospital is by one's car or the use of a $120 \quad \begin{array}{llllllllll}56 & 57 & 26 & 21 & 9 & 22 & 9 & 0 & 0\end{array}$ drop.

$S A=$ Strongly Agreed, $A=$ Agreed, $S D=$ Strongly Agreed, $D=$ Disagreed and $U=$ Undecided .

\subsection{Research Question 2: What is the Perception of Clients on the Level of Hospital in the Reduction of Maternal Mortality in Calabar?}

From Table 3, 6 questions were used to elicit answers to the research question. Question 11 was to find out the perception of respondents on the hospital being at the highest level hospital. 74 (33\%) strongly agreed, 62 (28\%) agreed, $50(23 \%)$ strongly disagreed, $28(13 \%)$ disagreed while $6(3 \%)$ were undecided. Question 12 was on how skilled the midwives and doctors are $128(59 \%)$ strongly agreed, $75(34 \%)$ disagreed, $14(6 \%)$ strongly disagreed and $3(1 \%)$ disagreed. Question 13 was on the perception of low death rate in pregnancy-associated conditions in the hospital. $101(46 \%)$ strongly agreed, $42(19 \%)$ agreed, 38 (17\%) strongly disagreed, $28(13 \%)$ disagreed and $11(5 \%)$ were undecided. Question 14 was on if the level of the hospital is reflective of the low maternal and infant death rate. $87(40 \%)$ strongly agreed, $65(30 \%)$ agreed, $47(21 \%)$ strongly disagreed, $13(6 \%)$ disagreed, while $8(3 \%)$ were undecided. Question 15 was on if the healthcare team are highly skilled in handling both complicated and uncomplicated deliveries. 93 (42\%) strongly agreed, 66 (30\%) agreed, 39 (18\%) strongly disagreed, while $22(10 \%)$ disagreed. Question 16 was if the cost of delivery is moderate compared to other hospitals. 67 (30\%) strongly agreed, 78 (36\%) agreed, $42(19 \%)$ strongly disagreed, $28(13 \%)$ disagreed while 5 $(2 \%)$ were undecided. Question 17 was on the quality of maternal and child care in the hospital is exceptional. 94 (43\%) strongly agreed, $68(31 \%)$ agreed, $37(17 \%)$ strong disagreed, $12(5 \%)$ disagreed while $9(4 \%)$ were undecided.

Table 3. The perception of clients on the level of hospital in the reduction of maternal mortality in Calabar $(\mathrm{n}=220)$

\begin{tabular}{|c|c|c|c|c|c|c|c|c|c|c|c|}
\hline & Items & SA & $\%$ & $\mathbf{A}$ & $\%$ & SD & $\%$ & $\mathbf{D}$ & $\%$ & $\mathbf{U}$ & $\%$ \\
\hline 11 & Teaching hospital is a tertiary hospital (at the highest level) & 74 & 33 & 62 & 28 & 50 & 23 & 28 & 13 & 6 & 3 \\
\hline 12 & The hospital has skilled midwives and doctors & 128 & 59 & 75 & 34 & 14 & 6 & 3 & 1 & 0 & 0 \\
\hline 13 & $\begin{array}{l}\text { I think the death rate from pregnancy, labour and delivery in } \\
\text { the hospital is very low }\end{array}$ & 101 & 46 & 42 & 19 & 38 & 17 & 28 & 13 & 11 & 5 \\
\hline 14 & $\begin{array}{l}\text { The level of the hospital is reflective of low maternal and } \\
\text { infant deaths }\end{array}$ & 87 & 40 & 65 & 30 & 47 & 21 & 13 & 6 & 8 & 3 \\
\hline 15 & $\begin{array}{l}\text { The healthcare team are highly skilled in handling both } \\
\text { complicated and uncomplicated deliveries }\end{array}$ & 93 & 42 & 66 & 30 & 39 & 18 & 22 & 10 & 0 & 0 \\
\hline 16 & The cost of delivery is moderate compared to other hospitals & 67 & 30 & 78 & 36 & 42 & 19 & 28 & 13 & 5 & 2 \\
\hline 17 & $\begin{array}{l}\text { The quality of maternal and child care in the hospital is } \\
\text { exceptional }\end{array}$ & 94 & 43 & 68 & 31 & 37 & 17 & 12 & 5 & 9 & 4 \\
\hline
\end{tabular}

$S A=$ Strongly Agreed, $A=$ Agreed, $S D=$ Strongly Agreed, $D=$ Disagreed and $U=$ Undecided.

\subsection{Research Question 3: What are the Transport-related Barriers that Delay Access to Maternal Health Services in UCTH?}

Five (5) questions were used to elicit answers to research question 3 (Table 4). Question 18 asked if bad roads prevent easy access to maternal health services in UCTH. Responses show that $82(37 \%)$ strongly agreed, 67 (30\%) agreed, $41(19 \%)$ strongly disagreed, 22(10\%) disagreed while 8(4\%) were undecided. Question 19 was on if bad transport vehicles prevent easy access to maternal health services in UCTH. 77 (35\%) strongly agreed, 85(39\%) agreed, 41(19\%) strongly disagreed, 17 (7\%) disagreed. Question 20 was if unreliable transport system prevents easy access to maternal health services in UCTH. 80 (36\%) strongly agreed, 72 (33\%) agreed, 32 (15\%) strongly disagreed, $26(12 \%)$ disagreed while $10(4 \%)$. Question 21 was on if the cost of transportation prevents easy access to maternal health services in UCTH. Responses show that 55 (25\%) strongly agreed, 63 (28\%) 
agreed, 70 (32\%) strongly disagreed, and 32 (15\%) disagreed. Question 22 was on if emergency Transportation is poor and unreliable to access. $120(56 \%)$ strongly agreed, $65(30 \%)$ agreed, $18(8 \%)$ strongly disagreed, while $17(7 \%)$ disagreed.

Table 4. The transport-related barriers that delay access to maternal health services in UCTH $(n=220)$

\begin{tabular}{|c|c|c|c|c|c|c|c|c|c|c|c|}
\hline & Items & SA & $\%$ & $\mathbf{A}$ & $\%$ & SD & $\%$ & D & $\%$ & $\mathbf{U}$ & $\%$ \\
\hline 18 & $\begin{array}{l}\text { Bad roads prevent easy access to maternal health services in } \\
\text { UCTH }\end{array}$ & 82 & 37 & 67 & 30 & 41 & 19 & 22 & 10 & 8 & 4 \\
\hline 19 & $\begin{array}{l}\text { Bad transport vehicles prevent easy access to maternal health } \\
\text { services in UCTH }\end{array}$ & 77 & 35 & 85 & 39 & 41 & 19 & 17 & 7 & 0 & 0 \\
\hline 20 & $\begin{array}{l}\text { Unreliable transport system prevent easy access to maternal } \\
\text { health services in UCTH }\end{array}$ & 80 & 36 & 72 & 33 & 32 & 15 & 26 & 12 & 10 & 4 \\
\hline 21 & $\begin{array}{l}\text { The cost of transportation prevent easy access to maternal health } \\
\text { services in UCTH }\end{array}$ & 55 & 25 & 63 & 28 & 70 & 32 & 32 & 15 & 0 & 0 \\
\hline 22 & Emergency Transportation is poor and unreliable to access. & 120 & 56 & 65 & 30 & 18 & 8 & 17 & 7 & 0 & 0 \\
\hline
\end{tabular}

$S A=$ Strongly Agreed, $A=$ Agreed, $S D=$ Strongly Agreed, $D=$ Disagreed and $U=$ Undecided .

\subsection{Research Question 4 what are the Importance of Road in the Reduction of Maternal Mortality in Calabar?}

From Table 5, five questions were asked to meet the objective 4. Question 22 was on transportation plays a huge role in the reduction of maternal mortality in Calabar. 93 (94\%) strongly agreed, 78 (35\%) agreed, $12(6 \%)$ strongly disagreed, $25(11 \%)$ disagreed while 12 (6\%) were undecided. Question 23 dwelt on good road network have an indirect role in reducing maternal mortality in Calabar. The analysis of data shows that 66 (30\%) strongly agreed, 82 (37\%) agreed, 47 (21\%) agreed, $23(11 \%)$ disagreed while $2(1 \%)$ disagreed. Question 24 centred on is controlled traffic helps in reducing maternal mortality in Calabar. 68 (31\%) strongly agreed, 78 (36\%) agreed, 46 (20\%) strongly disagreed, 20 (10\%) disagreed and $8(4 \%)$ were undecided. Question 25 was emergency vehicles such as ambulance is a good transport medium that reduces maternal death. 73 (33\%) strongly agreed, 67 (31\%) agreed, 58 (26\%) strongly disagreed, and 22 (10\%) disagreed. The last question 26 emphasised if lack of access to transport for women in labour can increase stillbirth and maternal death rates. 89 (40\%) strongly agreed, $70(31 \%)$ agreed, 32 (15\%) strongly disagreed, $17(8 \%)$ disagreed while $12(6 \%)$ were undecided.

Table 5. The importance of road in the reduction of maternal mortality in Calabar

\begin{tabular}{|c|c|c|c|c|c|c|c|c|c|c|c|}
\hline & Items & $\mathbf{S A}$ & $\%$ & $\mathbf{A}$ & $\%$ & SD & $\%$ & D & $\%$ & $\mathbf{U}$ & $\%$ \\
\hline 22 & $\begin{array}{l}\text { Transportation plays a huge role in the reduction of maternal } \\
\text { mortality in Calabar }\end{array}$ & 93 & 42 & 78 & 35 & 12 & 6 & 25 & 11 & 12 & 6 \\
\hline 23 & $\begin{array}{l}\text { Good road network has an indirect role in reducing maternal } \\
\text { mortality in Calabar }\end{array}$ & 66 & 30 & 82 & 37 & 47 & 21 & 23 & 11 & 2 & 1 \\
\hline 24 & Controlled traffic helps reduced maternal mortality in Calabar & 68 & 31 & 78 & 36 & 46 & 20 & 20 & 10 & 8 & 4 \\
\hline 25 & $\begin{array}{l}\text { Emergency vehicles such as ambulance is a good transport } \\
\text { medium that reduces maternal death }\end{array}$ & 73 & 33 & 67 & 31 & 58 & 26 & 22 & 10 & 0 & 0 \\
\hline 26 & $\begin{array}{l}\text { Lack of access to transport for women in labour can increase } \\
\text { stillbirth and maternal death rates. }\end{array}$ & 89 & 40 & 70 & 31 & 32 & 15 & 17 & 8 & 12 & 6 \\
\hline
\end{tabular}

\section{Discussion of Findings}

The results of socio-demographic data showed that majority of the respondents were age between 25-34 years; large populations of respondents were civil servants. 


\subsection{Clients Perceive the Role of Transportation to the Hospital in Calabar}

Transportation is very important in the quality of services provided in the hospital. Effective transportation plays a huge role in prompt healthcare services, especially for emergency and referral. Unfortunately, this is not always the case. The poor road network in developing countries adds to the already existing health challenges. From the analysis, $153(68 \%)$ agreed that good transportation increases the number of times participants go for an antenatal visit. $150(68 \%)$ of the participants go for an antenatal visit with access to antenatal visit. 114 (53\%) opined that bad road causes waste pain following a long drive to antenatal visit. $108(49 \%)$ of the respondents thought that traffic during rush hour is frustrating as they have to get to the clinic early. $159(72 \%)$ of the respondents viewed that good roads and vehicles make a journey to the hospital quick and easy. $165(70 \%)$ of the respondents suggest that commercial vehicles are not conducive for pregnant women. $177(62 \%)$ opined that the best way to visit the hospital is by one's car or a taxi drop. These findings are not new. The previous study has suggested that it is important to understand the perceptions of road users and their satisfaction in a bid to improving transport services especially in health (Vicente \& Reis, 2016). In some developing counties, the cost of emergency transportation is very expensive. Pregnant women who live a kilometre from the hospital do not take transport however, patients who live far of like Antigua and Egerton always experience unnecessary delays (Hirose et al., 2015). According to Hall et al. (2006), “...Adequate and appropriate vehicles, which are efficiently managed, are essential for the delivery of quality healthcare within a health system". The findings of the study also agree with the findings of a study in Oman which found that "people's attitudes towards using public transport and the role of transport are positive; however, they much prefer to use their cars. The nearest substitute to the personal car is the taxi, which largely fulfils the role of public transport, barring very few bus lines". Distance is often used as a proxy in accessing healthcare services and as such, there is the need to bridge the distance through the construction of good road networks.

\subsection{Perception of Clients on the Level of Hospital in the Reduction of Maternal Mortality in Calabar}

Analysis from table 3 shows that $136(61 \%)$ of the respondents agreed that Teaching Hospital Calabar is a tertiary hospital; 203 (93\%) agreed that hospital has skilled midwives and doctors; 143 (65\%) agreed that death rate from pregnancy, labour and delivery in the hospital is very low; $153(70 \%)$ agreed that level of the hospital is reflective of low maternal and infant deaths; $159(72 \%)$ agreed that healthcare team are highly skilled in handling both complicated and uncomplicated deliveries; 145 (66\%) agreed that the cost of delivery is moderate compared to other hospitals, and $162(74 \%)$ believed that the quality of maternal and child care in the hospital is exceptional. These findings are not new. Timane, Oche, Umar, Constance and Raji (2017) in their study found that there is a high level of satisfaction with services rendered in health institutions and encouraged for more access to the health facilities, and increasing communication between patients and staff and among staff. The study is in agreement with the World Health Organisation (1998) which recommends hospitals to improve quality of health services rendered to women to include cost-effective high-quality healthcare service, equitable healthcare service, effective care service, and improved staff morale. The perception of pregnant women on improvement in maternal mortality often increases the utilization of maternal and child health services in an institution (Ssengooba et al., 2003; Lubbock \& Stephenson, 2008). Nnebue and colleagues (2014) in their study concludes that the knowledge of client on the health service provided was good and the respondents were comfortable with the cost, local language used, staff attitude and interaction with clients in the hospital. Being a tertiary hospital, The University of Calabar Teaching Hospital is expected to provide quality healthcare services with reduced maternal mortality rate which the hospital currently maintains.

\subsection{Transport-Related Barriers that Delay Access to Maternal Health Services in UCTH}

Good transport is an important section in accessing healthcare services. Transportation serves as a direct link between clients' homes and the hospital. Unfortunately, in developing countries like Nigeria, poor road network and absence of regular means of suitable transport leave rural areas inaccessible, making physical access to specialized health care, which is not provided in local health facilities, difficult (Buor, 2004; Fay, Leipziger, Wodon, \& Yepes, 2005; Galaa \& Daare, 2008). Analysis of Table 4 shows that 149 (67\%) of respondents opined that bad roads prevent easy access to maternal health services in UCTH; $162(74 \%)$ of the respondents agreed that bad transport vehicles prevent easy access to maternal health services in UCTH; $152(69 \%)$ agreed that unreliable transport system prevents easy access to maternal health services in UCTH; 118 (53\%) agreed that the cost of transportation prevents easy access to maternal health services in UCTH, and 185 (86\%) agreed that emergency transport is poor and unreliable to access. The study is in line with Atuoye et al. (2015) which concluded that physical barriers to hospitals in the form of transport should be addressed as they can hinder the utilization of such hospital services. Also prolonged time of travel, cost of transportation, conditions of the roads 
and vehicles pose as transport barriers to accessing quality healthcare services (Varela et al., 2019). Delay accessing to transport increases maternal and infant mortality. Finding from this study supports an earlier study by Amare, Dibaba, Bayu and Hussien (2019) which suggests that the most common delay experienced by clients in their study was transport difficulties. Rajé (2018) suggest that failure of transport services increases maternal mortality and thus stressed the importance of improving transportation and roads to reduce maternal and child mortality.

\subsection{Hindrances to Access to Hospital Infrastructure in the Provision of Maternal Healthcare Services in UCTH}

Several factors hinder easy access to maternal and child health services in hospitals. One of such is seasonal variations. Makanga and colleagues (2017) in their study on "seasonal variation in geographical access to maternal health services in regions of southern Mozambique" found that there is a constant variation between the dry and wet seasons. The impact of bad roads and poor transport is hugely felt during the wet season as the depth of portholes and lack of constriction at the site is very evident during the wet season. Bad roads are manageable in the dry season. Findings from the study reveal that $181(78 \%)$ supports the notion that transportation plays a huge role in the reduction of maternal mortality in Calabar; 148 (67\%) agreed that good road network has an indirect role in reducing maternal mortality in Calabar; $146(67 \%)$ opined that controlled traffic helps reduced maternal mortality in Calabar; 140 (64\%) agreed that emergency vehicles such as ambulances are a good transport medium that reduces maternal death and 159 (71\%) agreed that lack of access to transport for women in labour can increase stillbirth and maternal death rates. This study supports Milkowska-Shibata et al. (2020). In their study, they identified barriers to accessing healthcare facilities to include transportation, health infrastructure in the rural areas. Also, Miteniece and colleagues (2018) opined that geographical barriers involving transport contribute to a decrease in accessing health facilities.

\section{Conclusion}

Transportation is an important sector that impacts on healthcare. This study focused on the role of transportation in reducing maternal mortality in Calabar. Participants in the study opined that bad roads prevent easy access to maternal health services, bad transport vehicles prevent easy access to maternal health services, unreliable transport system prevents easy access to maternal health services cost of transportation prevents easy access to maternal health services, that emergency transport is poor and unreliable to access. Transportation plays a huge role in the reduction of maternal mortality in Calabar, good road network has an indirect role in reducing maternal mortality, controlled traffic helps reduced maternal mortality in Calabar; emergency vehicles such as ambulances are a good transport medium that reduces maternal death and lack of access to transport for women in labour can increase stillbirth and maternal death rates. The study, therefore, concludes that a good road network should be provided to reduce maternal mortality in Calabar.

\section{The Implication of the Study to Nursing Practice}

Transportation is important in accessing maternal and child health services in health institutions. Nurses and midwives need to encourage antenatal visits as well as home visits especially for pregnant women who are accessing the hospital from distant rural areas which are more than twenty (20) kilometres away from the hospital. Complaints about the impact of long journeys on the body will always be presented during history taking. It is important nurses and midwives provides psychological support to women with such complaints. The government has a lot to do if the maternal mortality rate is to reduce. One of such ways is to improve the road network in Calabar as well as the transportation system and emergency transport.

\section{Acknowledgements}

Dr Emon Umoh Duke- Data analysis and discussion of findings.

Lukpata Felicia- Data analysis and methodology.

Ndukaku Nwakwue C- Review of literature and discussion of findings.

Agba Mathias- Data collection and ethical approval.

\section{Competing Interests Statement}

The authors declare that there are no competing or potential conflicts of interest.

\section{References}

Abegunde, D., Kabo, I. A., Sambisa, W., Akomolafe, T., Orobaton, N., Abdulkarim, M., \& Sadauki, H. (2015). Availability, utilization, and quality of emergency obstetric care services in Bauchi State, Nigeria. International Journal of Gynecology \& Obstetrics, 128(3), 251-255. 
https://doi.org/10.1016/j.ijgo.2014.09.029

Admasu, K., Haile - Mariam, A., \& Bailey, P. (2011). Indicators for availability, utilization, and quality of emergency obstetric care in Ethiopia, 2008. International Journal of Gynecology \& Obstetrics, 115(1), 101-105. https://doi.org/10.1016/j.jigo.2011.07.010

Alkema, L., Chou, D., Hogan, D., Zhang, S., Moller, A. B., Gemmill, A., ... \& Say, L. (2016). Global, regional, and national levels and trends in maternal mortality between 1990 and 2015, with scenario-based projections to 2030: a systematic analysis by the UN Maternal Mortality Estimation Inter-Agency Group. The Lancet, 387(10017), 462-474. https://doi.org/10.1016/S0140-6736(15)00838-7

Amare, Y. W., Dibaba, B., Bayu, M., \& Hussien, M. (2019). Factors associated with maternal delays in utilising emergency obstetric care in Arsi Zone, Ethiopia. South African Journal of Obstetrics and Gynaecology, 25(2), 56-63. https://doi.org/10.7196/sajog.1437

Atuoye, K. N., Dixon, J., Rishworth, A., Galaa, S. Z., Boamah, S. A., \& Luginaah, I. (2015). Can she make it? Transportation barriers to accessing maternal and child health care services in rural Ghana. BMC health services research, 15(1), 333. https://doi.org/10.1186/s12913-015-1005-y

Buor, D. (2004). Gender and the utilisation of health services in the Ashanti Region, Ghana. Health policy, 69(3), 375-388. https://doi.org/10.1016/j.healthpol.2004.01.004

Campbell, O. M., Graham, W. J., \& Lancet Maternal Survival Series steering group. (2006). Strategies for reducing maternal mortality: getting on with what works. The Lancet, 368(9543), 1284-1299. https://doi.org/10.1016/S0140-6736(06)69381-1

Fay, M., Leipziger, D., Wodon, Q., \& Yepes, T. (2005). Achieving child-health-related Millennium Development Goals: The role of infrastructure. World Development, 33(8), 1267-1284. https://doi.org/10.1016/j.worlddev.2005.03.001

Fiagbe, P., Asamoah, D., \& Oduro, F. T. (2012). Assessing the role of transport in the achievement of maternal mortality reduction in ghana. https://doi.org/10.5539/ijbm.v7n5p256

Galaa, S. Z., \& Daare, K. (2008). Understanding barriers to maternal child health services utilisation in northern Ghana. Journal of Social Development in Africa, 23(2). https://doi.org/10.4314/jsda.v23i2.54260

Haines, A., McMichael, A. J., Smith, K. R., Roberts, I., Woodcock, J., Markandya, A., ... \& Bruce, N. (2009). Public health benefits of strategies to reduce greenhouse-gas emissions: overview and implications for policymakers. The Lancet, 374(9707), 2104-2114. https://doi.org/10.1016/S0140-6736(09)61759-1

Hall et al. (2006, as cited by Broni, A. O., Aikins, I., Asibey, O., \& Agyemang-Duah, P., 2014). The contribution of transport (road) in healthcare delivery 'a case study of Mankranso District Hospital in the Ahafo Ano South District of Ashanti Region'. British Journals of Marketing Studies, 2(4), 30-51.

Hirose, A., Borchert, M., Cox, J., Alkozai, A. S., \& Filippi, V. (2015). Determinants of delays in travelling to an emergency obstetric care facility in Herat, Afghanistan: an analysis of cross-sectional survey data and spatial modelling. BMC pregnancy and childbirth, 15(1), 14. https://doi.org/10.1186/s12884-015-0435-1

Kim, Y. M., Zainullah, P., Mungia, J., Tappis, H., Bartlett, L., \& Zaka, N. (2012). Availability and quality of emergency obstetric and neonatal care services in Afghanistan. International Journal of Gynecology \& Obstetrics, 116(3), 192-196. https://doi.org/10.1016/j.ijgo.2011.10.017

Kitui, J., Lewis, S., \& Davey, G. (2013). Factors influencing place of delivery for women in Kenya: an analysis of the Kenya demographic and health survey, 2008/2009. BMC pregnancy and childbirth, 13(1), 40. https://doi.org/10.1186/1471-2393-13-40

Lubbock, L. A., \& Stephenson, R. B. (2008). Utilization of maternal health care services in the department of Matagalpa, Nicaragua. Revista Panamericana de Salud Pública, 24, 75-84. https://doi.org/10.1590/S1020-49892008000800001

Makanga, P. T., Schuurman, N., Sacoor, C., Boene, H. E., Vilanculo, F., Vidler, M., ... \& Firoz, T. (2017). Seasonal variation in geographical access to maternal health services in regions of southern Mozambique. International journal of health geographics, 16(1), 1-16. https://doi.org/10.1186/s12942-016-0074-4

Milkowska-Shibata, M. A., Aye, T. T., Yi, S. M., Oo, K. T., Khaing, K., Than, M., ... \& Ringstad, K. M. (2020). Understanding Barriers and Facilitators of Maternal Health Care Utilization in Central Myanmar. International Journal of Environmental Research and Public Health, 17(5), 1464. 
https://doi.org/10.3390/ijerph17051464

Miteniece, E., Pavlova, M., Shengelia, L., Rechel, B., \& Groot, W. (2018). Barriers to accessing adequate maternal care in Georgia: a qualitative study. BMC health services research, 18(1), 631. https://doi.org/10.1186/s12913-018-3432-z

Nguyen, T. H. T., McDonald, F., \& Wilson, A. (2017). Health workers' perspectives on infrastructure to support maternal health services in rural areas of Vietnam. Asia-Pacific Journal of Health Management, 12(2), 55-61. https://doi.org/10.24083/apjhm.v12i2.81

Nnebue, C. C., Ebenebe, U. E., Adinma, E. D., Iyoke, C. A., Obionu, C. N., \& Ilika, A. L. (2014). Clients' knowledge, perception and satisfaction with the quality of maternal health care services at the primary health care level in Nnewi, Nigeria. Nigerian Journal of clinical practice, 17(5), 594-601. https://doi.org/10.4103/1119-3077.141425

Rajé, F. (2018). Rural transport interventions to improve maternal health outcomes. Retrieved June 20, 2020, from https://opendocs.ids.ac.uk/opendocs/handle/20.500.12413/13948.

Shrestha, S. K., Banu, B., Khanom, K., Ali, L., Thapa, N., Stray-Pedersen, B., \& Devkota, B. (2012). Changing trends on the place of delivery: why do Nepali women give birth at home? Reproductive health, 9(1), 25 . https://doi.org/10.1186/1742-4755-9-25

Ssengooba, F., Neema, S., Mbonye, A., Sentubwe, O., \& Onama, V. (2003). Maternal health review Uganda. Unpublished report.] Health Systems Development Programme, Makerere University Institute of Public Health, Kampala.

Timane, A. J., Oche, O. M., Umar, K. A., Constance, S. E., \& Raji, I. A. (2017). Clients' satisfaction with maternal and child health services in primary health care centres in Sokoto metropolis, Nigeria. Edorium Journal of Maternal and Child Health, 2, 9-18.

Umoe, D. E., Esienumoh, E. E., Regina E. E., Nwakwue, N. C., \& Mathias, A. (2020a). Perception of prenatal exercise and its perceived outcome among pregnant women attending antenatal clinic at the University of Calabar Teaching Hospital. Global Journal of Health Science, 12(8), 157-165. https://doi.org/10.5539/gjhs.v12n8p157

Umoe, D. E., Regina E. E., Esienumoh, E. E., Nwakwue, N. C., \& Catherine, T. (2020b). Stress-related factors among nurses working in accident and emergency in a selected federal government hospital in South-South Nigeria. Global Journal of Health Science, 12(8), 166-175 https://doi.org/10.5539/gjhs.v12n8p166

Varela, C., Young, S., Mkandawire, N., Groen, R. S., Banza, L., \& Viste, A. (2019). Transportation barriers to accessing health care for surgical conditions in Malawi a cross-sectional nationwide household survey. $B M C$ public health, 19(1), 264. https://doi.org/10.1186/s12889-019-6577-8

Vicente, P., \& Reis, E. (2016). Profiling public transport users through perceptions about public transport providers and satisfaction with the public transport service. Public Transport, 8(3), 387-403. https://doi.org/10.1007/s12469-016-0141-z

World Health Organisation [WHO]. (1998). World Health Day safe Motherhood 1998. Retrieved from https://www.who.int/docstore/world-health-day/en/pages1998/whd98_08.html

World Health Organization [WHO]. (2019). Maternal mortality Key facts. Retrieved February 20, 2020, from https://www.who.int/news-room/fact-sheets/detail/maternal-mortality.

\section{Copyrights}

Copyright for this article is retained by the author(s), with first publication rights granted to the journal.

This is an open-access article distributed under the terms and conditions of the Creative Commons Attribution license (http://creativecommons.org/licenses/by/4.0/). 